\title{
Komunikasi Instruksional Di Kelas Yoga Club Health Fatimah Kota Serang
}

\author{
Indrianti Azhar Firdausi. M.Ikom \\ Fakultas Ilmu Sosial, Ilmu Politik dan Ilmu Hukum, Universitas Serang Raya \\ email: indriantiazhar@gmail.com
}

\begin{abstract}
Yoga is a sport that is much in demand by sports lovers today even though yoga is always identified with meditation and religious rituals. Moreover, the emergence of yoga in the city of Serang could bring concern to the local community which is thick with a devout Islamic religion, but over time yoga was accepted and had space by opening a yoga class at the Fatimah Health Club in Serang City. The implementation of the vinyasa yoga exercise instruction prioritizes breathing arrangements with the aim of harmony of body and soul. This study uses the concept of instructional communication and cognitive learning theory to find out how to think, instruction to interpret yoga and the implementation of yoga instruction through breathing, posture of movement to the use of the language of yoga instruction. Use The research method is a case study with data collection techniques through interviews, observation and documentation
\end{abstract}

Keywords: Yoga, Instructional communication, cognitive learning

\section{PENDAHULUAN}

Yoga adalah salah satu jenis olahraga yang pamornya terus menanjak di publik dalam beberapa tahun belakang. Yoga berasal dari bahasa sansekerta yang berarti penyatuan jiwa dan kesadaran yang tak terbatas serta jiwa dan kesadaran yang universal dan ilahi. Dalam hal ini berarti olahraga yoga sebuah aktivitas fisik yang melibatkan meditasi dengan teknik peregangan, pernapasan, keseimbangan, dan kelenturan tubuh sehingga mampu mengontrol, mengatur dan berkonsentrasi penuh sehingga dapat menciptakan keselarasan serta keseimbangan antara pikiran, jiwa dan tubuh. Dalam sejarahnya yoga telah diptraktikkan sejak 4000 tahun yang lalu di India baru kemudian dikenal di Eropa 30 tahun terakhir khususnya berkembang pesat di Amerika dimana yoga bukan sekedar kebutuhan untuk berlatih atau kesehatan fisik namun sudah menjadi bagian dari gaya hidup. Selain yoga centers yang menyebar hampir di seluruh pelosok negeri, kelengkapan pendukung latihan pun turut menyertainya seperti kaus, celana, matras yoga, atau alat bantu lainnya yang kerap dipakai dalam latihan fisik. Asosiasi-asosiasi yoga pun terbentuk seiring pertumbuhannya, bahkan terdapat International Yoga
Alliance (IYA) yang dikreasi oleh masyarakat Amerika. Mereka membuat standard dan ketentuan, seperti kurikulum dalam menyelenggarakan pelatihan bagi para yogi (teacherr training), meskipun yoga berasa dari India namun pengemasan dalam pemasaran yoga lebih berkembang di Amerika.

Di Indonesia sendiri, senam yoga mulai dikenal tahun 90-an. Dalam delapan tahun terakhir perkembangan untuk berlatih yoga di Indonesia meningkat pesat khususnya di ibukota Jakarta. Animo dan minat masyarakat yang berlatih yoga menunjukan grafik yang meningkat. Selain itu, pemberitaan dan publikasi di media baik cetak maupun elektronik dengan memanfaatkan olahraga yoga sebagai gimmick juga semakin banyak.

Sudah menjadi gaya hidup, banyak artis Indonesia juga ikut menggandrungi olahraga yoga, salah satu pasangan seniman yang mempopulerkan yoga di Indonesia adalah Anjasmara dan Dian Nitami, mereka konsisten terhadap olahraga ini dan menjadi instruktur yoga setelah menyelesaikan training Yoga Teacher Training selama 300 jam. Belum lagi maraknya penggunaan media sosial sebagai media promosi diri tak luput dari kegiatan para seniman berbagi cerita 
tentang minat mereka terhadap olahraga yoga seperti Sophia Latjuba, Pevita Pearce, Marshanda, Yuni Shara hingga Inul Daratista. Melalui postingan para seniman inilah masyarakat terinspirasi dan mulai banyak yang mencoba yoga.

Olahraga Yoga di Banten sendiri muncul pada tahun 2012 di Kota Cilegon dan Kota Serang, di tengah maraknya olahraga seperti Aerobik, Pilates, dan Zumba dengan charge instruktur tak lebih dari dua puluh ribu rupiah dalam sekali latihan. Sementara Yoga kurang diminati diawal kemunculannya karena charge instruktur latihan yang cukup mahal yaitu lima puluh ribu rupiah, belum lagi yoga identik dengan olahraga yang disertai meditasi dan dianggap sebagai bagian dari ritual agama sehingga sulit di terima oleh masyarakat Kota Serang yang kental dengan masyarakat muslim taat. Namun, mengantisipasi hal tersebut beberapa instruktur yoga memilih jenis yoga beraliran Vinyasa yaitu jenis yoga yang fokus dalam melatih pernafasan. Kebanyakan gerakan mudah dipelajari oleh pemula yang baru mengenal olahraga yoga dengan manfaat menguatkan beberapa organ inti tubuh sekaligus relaksasi dengan memberikan ketenangan dan melancarkan peredaran darah. Gerakan yoga Vinyasa dikenal dengan nama flow yoga yaitu gerakan penuh ritme dan dinamis dimana gerakan dilakukan secara perlahan dan selaras dengan proses bernafas. Gerakan yoga vinyasa terasa lambat dan membosankan, namun instruktur yoga berinovasi pada setiap pertemuan dengan memodifikasi gerakan-gerakan yoga lainnya dan menggunakan alat olahraga selain matras yoga

Kelas Olahraga yoga mulai dibuka di bawah manajeman Rumah Sakit Ibu dan Anak Fatimah yang mempunyai dua klinik di Kota Cilegon dan Kota Serang dalam Health Club Fatimah. Bekerjasama dengan instruktur yoga senior dan profesional bersertifikat jam terbang 300 jam, anggota olahraga ini bertambah setiap tahunnya yang diikuti kebanyakan kaum wanita pekerja, Ibu Rumah Tangga hingga ibu hamil karena gerakan olahraga yoga juga dipercaya dapat membantu memudahkan persalinan pada ibu hamil.. Hal tersebut itulah menjadi tujuan penelitian ini dan menjadi tantangan tersendiri bagi instruktur yoga. Pertama,. transfer instruksi cara berfikir instruktur mengenai olahraga yoga kepada anggotanya. Kedua, untuk menyamaratakan makna olahraga yoga agar anggota tetap mencintai olahraga ini. Ketiga, untuk mengetahui pelaksanaan instruksi instruktur yoga di kelas yoga. Dengan latar belakang di atas peneliti merumuskan penelitian mengenai Komunikasi Instruksional pada kelas yoga di Health Club Fatimah Serang.

\section{KAJIAN LITERATUR}

Landasan konsep komunikasi pada penelitian ini adalah komunikasi instruksional, dimana menurut Smithe dalam Yusuf (Komunikasi Instruksional, 2010:65) proses instruksional terjadi manakala seseorang membantu orang lain dalam mengubah perilaku. Karena proses ini disengaja dan diupayakan terjadinya, maka faktor keahlian berkomunikasi menjadi amat penting. Baik dalam tingkatan yang sederhana maupun dalam tingkatan yang kompleks, menjadi bagian yang tidak bisa diabaikan fungsinya. Para pengajar, instruktur, atau para praktisi komunikasi lainnya di lapangan apabila menghadapi suatu kelas tentu mempunyai dasar pijakan yang berbeda satu sama lain walaupun tujuannya sama, yaitu melaksanakan kegiatan instruksional. Seperti kelas yoga di health club fatimah dasar pijakan instruksinya adalah latihan yoga namun dimodifikasi sesuai dengan budaya dan masyarakatnya.

Hal ini menjadi tolak ukur dalam pengembangan instruksional sesuai dengan situasi komponen di dalamnya seperti siswa, pengajar, kurikulum dan fasilitas belajar yang tersedia. Kegiatan instruksional pada intinya juga adalah proses pembantuan agar terjadi perubahan perilaku pada pihak sasaran, dimana terdapat unsur memengaruhi, terutama dari pihak pengajar atau instruktur meskipun dengan maksud dan tujuan yang bersifat positif.

Teori penelitian ini menggunakan teori belajar kognitif. Teori belajar 
kognitif berasal dari pandangan Kurt Lewin (1890-1947) dalam Yusuf (2016) yang banyak membicarakan masalah persepsi dan motivasi. Persepsi dasar dari psikologi kognitif adalah berpikir secara sadar. Belajar selanjutnya dibatasi sebagai proses komunikasi dan interaksional pada manusia dalam memperoleh insight (wawasan) baru. Dengan begitu hal ini merupakan perubahan dalam struktur kognitif, dan termasuk wawasan itu sendiri. Untuk kepentingan belajar secara kognitif, maka orang harus concern dan berinteraksi, berkomunikasi untuk menerima dan menyampaikan informasi dan bersosialisasi dengan orang lain. (Yusuf, 2010: 148-149)

Teori belajar kognitif banyak digunakan untuk membantu memperlancar para praktisi komunikasi di lapangan, seperti guru, instruktur, penyuluh lapangan, dan para komunikator Pendidikan. Dalam penelitian ini praktisi komunikasinya adalah instruktur yoga di kelas yoga health club Fatimah kota serang. Pertama, faktor berpikir mempunyai kedudukan penting dalam diri setiap orang, dan belajar menurut teori ini merupakan proses berpikir, sedangkan berpikir menggunakan logika. Untuk itu seorang komunikator perlu membentuk pola komunikasi agar mendapat perhatian dari peserta. Kedua, belajar pada prinsipnya adalah proses menggunakan logika atau berpikir, sedangkan berpikir merupakan upaya mental dalam memahami sesuatu yang bermakna. Belajar bisa bermakna apabila ada kesinambungan konsep dengan pola pemahaman atas informasi sebelumnya. Untuk itu dalam system instruksional seorang komunikator perlu memaknakan infomasi yang disampaikan kepada sasaran agar bisa dipahami dengan mudah. Ketiga, pelaksanaan instruksional perlu dirancang dengan memperhatikan tingkatan-tingkatan hierarkis sehingga pihak sasaran menjalani proses belajarnya dengan runtut sejalan perkembangan intelektualnya. (Yusuf, 2010:156-157)

Referensi penelitian sebelumnya mengenai yoga dilakukan oleh Arum Sukma Kinasih dengan judul "Pengaruh Latihan Yoga Terhadap Peningkatan
Kualitas Hidup" terbit di Buletin Psikologi tahun 2010 dengan hasil penelitian bahwa yoga mempengaruhi aspek fisik, psikologis dan spiritual melalui latihan yoga yang intens. Penelitian berikutnya oleh Kiki Zakiyah dan Muthiah Umar "Komunikasi Instruksional Dalam Proses Pembelajaran Mahasiswa" terbit di jurnal Mediator tahun 2006, dengan metode kuantitatif hasil penelitiannya menjelaskan spesifikasi isi dan tujuan instruksional sebagai pengalaman belajar mahasiswa di Unisba masih rendah, penafsiran perilaku mula dalam proses pembelajaran di Unisba cukup berarti, strategi instruksional dengan metode ceramah, organisasi satuan instruksional cukup signifikan, terakhir, kemampuan dosen dalam umpan balik pada komunikasi instruksional cukup baik.

\section{METODE PENELITIAN}

Studi kasus adalah sebuah eksplorasi dari suatu sistem yang terikat atau suatu kasus/beragan kasus yang dari waktu ke waktu melalui pengumpulan data yang mendalam serta melibatkan berbagai sumber informasi yang kaya dalam suatu konteks. Dengan perkataan lain, studi kasus merupakan penelitian dimana peneliti menggali suatu fenomena tertentu (kasus) dalam suatu waktu dan kegiatan serta mengumpulkan informasi secara terinci dan mendalam dengan menggunakan berbagai prosedur pengumpulan data selama periode tertentu.K.Yin, 2005:126)

Creswell dalam Wahyuningsih (2013) mengungkapkan bahwa studi kasus menggunakan sumber informasi yang meliputi: observasi dimana peneliti mengikuti langsung kelas yoga di health club fatimah serang, peneliti juga melakukan wawancara dengan instruktur yoga, peneliti melakukan dokumentasi dan laporan di lapangan. Fokus kasus di dalam suatu kasus dapat dilihat dari keunikannya yang disebut studi kasus instrinsik, dapat pula menjadi suatu isu (isu-isu) dengan menggunakan kasus sebagai instrumen untuk menggambarkan isu tersebut (studi kasus instrumental). Ketika suatu kasus diteliti lebih dari satu 
kasus hendaknya mengacu pada studi kasus kolektif. Penelitian ini menggunakan studi kasus instrinsik karena objek yang unik yaitu kelas olahraga yoga yang mulai diminati di tengah masyarakat Kota Serang yang lekat dengan masyarakat muslim. Sementara olahraga yoga identik dengan ritual keagamaan yang bertolak belakang dengan ritual agama muslim.

\section{HASIL DAN PEMBAHASAN}

Dalam komunikasi instruksional dengan dua elemennya yaitu pengajar (komunikator) dan pelajar (komunikan) sama-sama melakukan interaksi psikologi yang nantinya diharapkan dapat berdampak pada berubahnya pengetahuan, sikap dan ketrampilan di pihak komunikan. Proses interaksi ini berlangsung paling tidak antara dua orang dengan cara berkomunikasi, teknik atau alat untuk melaksanakan proses ini adalah komunikasi, yaitu komunikasi insruksional (Yusuf, 2010: 65)

Terdapat transfer belajar yang terjadi karena kondisi sturktur kognitif seseorang dalam ruang pengalamannya dikembangkan menjadi struktur kognitif orang yang bersangkutan dalam ruangan pengalamannya di masa yang akan datang (Bigge dalam Yusuf, 2010:155).

Manakala transfer belajar terjadi, maka bentuk generalisasi, konsep, dan wawasan, dikembangkan dari situasi yang satu kepada situasi yang lain. Konsep ini dinamakan transposisi. Transposisi dalam wawasan dapat dijelaskan dengan kebiasaan (habits) yaitu sebagai prinsip penerapan keahlian dalam satu situasi di mana dengan penerapan tersebut akan dapat membantu orang dalam mencapai tujuannya. Dalam kelas yoga di Health Club Fatimah Serang, penerapan kebiasaan pada anggota kelas yoga di mulai dengan beberapa tahapan. Diantaranya, membentuk cara berfikir anggota kelas yoga dalam berolahraga, kemudian membangun makna dalam kegiatan transformasi latihan yoga, baru kemudian instruksi pelaksanaan latihan yoga di kelas.

1. Instruksi Cara Berfikir Yoga
Kesamaan berfikir dalam proses belajar antara pengajar dan yang belajar perlu mendapat perhatian tersendiri karena tanpa kesamaan tersebut, kegiatan instruksional akan gagal. Diawal kelas bagi anggota yang baru mengikuti kelas yoga akan melakukan adaptasi-adaptasi dengan sharing informasi, karena motivasi setiap orang berolahraga berbeda ketika memutuskan bergabung dalam olahraga yoga. Olahraga yoga memang banyak jenisnya tergantung tujuannya, namun seiring perkembangan maka gerakan yoga banyak dimodifikasi sesuai dengan kebutuhan. Penelitian ini fokus pada kelas yoga dengan aliran vinyasa, yaitu olahraga yoga yang memfokuskan pada teknik pernafasan dengan tujuan menguatkan dan mengembalikan kondisi beberapa organ inti. Instruktur menyampaikan bahwa gerakan-gerakan pada yoga vinyasa memberikan manfaat pada tubuh seperti melancarkan peredaran darah dan memberikan ketenangan.

Mengkomunikasikan instruksi berfikir dalam olahraga yoga, pertama, bahwa tujuan anggota dalam beryoga adalah bukan untuk membentuk tubuh lebih proporsional namun lebih pada kesehatan organ dalam agar maksimal bersinergi satu sama lain.

Instruksi Kedua, instruktur akan mentransfer cara berfikir bahwa olahraga yoga sebagai suatu kegiatan olah seni dan jiwa, yoga mengombinasikan pengendalian pikiran, pernapasan dengan latihan fisik. Dimana gerakannya cenderung halus dan tidak terburu-buru karena yoga menciptakan keselarasan dalam tubuh melalui peningkatan fleksibilitas dan kekuatan otot tanpa gerakan tergesa-gesa yang hanya akan melukai sendi-sendi.

Instruksi ketiga, dalam olahraga yoga mempunyai semangat the noncompetitive spirit of yoga, yoga membawa semangat untuk melepaskan ego bahwa tak ada yang 
lebih benar dari lainnya. Maksudnya

jika dalam pose tertentu keseimbangan anggota belum sempurna, maka perlu berlatih rutin agar otot-otot semakin fleksibel sehingga tujuan anggota menampilkan postur tubuh makin sempurna dan tidak kaku dan kesempurnaan pose bukan menjadi kompetisi antar anggota, karena tujuan beryoga adalah mengontrol kesehatan dan emosi bukan mengutamakan pose yoga semata.

2. Instruksi Makna Beryoga

Seorang komunikator perlu berusaha memaknakan informasi yang disampaikan kepada sasaran agar bisa dipahami dengan mudah. Agar pelaksanaan instruksional runtut dan sampai ke instruksi yang rumit tapi mudah diingat. seperti apa itu olahraga yoga, tujuan beryoga, dan istilah-istilah dalam instruksi yoga. Dalam latihan yoga, instruktur yoga biasanya menyampaikan makna bahwa setiap postur yang diajarkan memiliki arti yang berbeda, baik dari tubuh maupun pikiran. Misalnya pada postur duduk dimaknai sebagai pose untuk relaksasi. Sementara postur berdiri dimaknai sebagai cara untuk membangkitkan energi.

Kemudian dalam posisi yoga, instruktur juga menyampaikan dua macam disiplin praktik, yaitu gerak dan diam ketika menginstruksikan pose-pose tertentu. Disiplin gerak bermanfaat untuk menguatkan fisik, menghilangkan kekakuan sendi dan otot, serta mengontrol kesehatan saraf dan kelenjar tubuh. Sementara disiplin diam mengajarkan cara untuk fokus memusatkan konsentrasi dengan manfaat dapat lebih mengontrol emosi serta meningkatkan daya ingat. Dimana sehat yang baik adalah sehat secara badan, jiwa dan pikiran juga termasuk di dalamnya ada keseimbangan antara badan, jiwa dan pikiran yang harus tetap terjaga agar terjalin koordinasi yang baik

3. Pelaksanaan Instruksional Yoga
Kualitas intelektual dan mental seseorang tidak sama, untuk itu faktor perbedaan individu menjadi perhatian instruktur dalam memperlakukan anggotanya di kelas yoga. Minat, bakat, kecerdasan dan motivasi setiap anggota banyak menentukan keberhasilan dalam mencapai tingkatan yoga yang baik. Seorang instruktur yoga seringkali berkaca pada setiap latihan yoga bersama muridnya, karena akan menjadi pertimbangan dalam meningkatkan kualitas beryoga dan memang setiap latihan pengalaman individu dalam beryoga akan memberi hasil yang berbeda-beda. Indikator olahraga yoga sudah dikuasai anggota adalah anggota mampu melakukan pose-pose yoga yang cukup rumit dan butuh tingkat konsentrasi tinggi. Namun level tersebut tidak dapat diimplementasikan pada setiap anggota pada waktu yang bersamaan karena setiap anggota memiliki bakat, kondisi serta motivasi yang berbeda dalam beryoga.

Dari 40 anggota kelas yoga di health club fatimah kota serang terbagi jadwal di hari selasa sore, kami pagi dan jumat siang. Dari kelas tersebut instruktur menginstruksikan tahapan yoga secara sistematis agar hasilnya berdampak baik secara optimal pada tubuh.

a. Instruksi Pernafasan

Vinyasa merupakan aliran yoga yang paling populer dan paling aman dari persepsi bahwa yoga adalah olahraga meditasi dan ritual, karena aliran vinyasa fokus pada teknik pernafasan. Teknik pernafasan adalah teknik yang paling penting dalam latihan yoga, karena akan berpengaruh pada kemajuan kondisi kesehatan. Pernafasan dilakukan dengan cara menarik nafas melalui hidung dan menghembuskan nafas melalui mulut. Saat menarik dan menghembuskan nafas udara 
masuk ke dalam tubuh membawa oksigen yang berfungsi sebagai "bahan bakar" untuk mengoptimalkan kinerja organorgan dalam tubuh. Dalam teknik pernafasan ini atau disebut juga dalam bahasa sankrit "Pranayama", anggota diminta untuk menarik nafas perlahan kemudian menahan nafas beberapa detik kemudian melepaskannya secara perlahan, diikuti instruksi membebaskan pikiran dari beban permasalahan hidup dengan mengambil hal positif dan membuang hal negatif melalui pernafasan.

Teknik pernafasan ini biasanya difokuskan pada posisi duduk dengan kedua tangan di atas lutut, telapak tangan menghadap atas dengan ibu jari menyentuh ujung telunjuk kiri dan kanan. Posisi ini disebut dengan "chin mudra" yang dapat membantu meningkatkan perasaan tenang diikuti pengaturan pernafasan. Selain itu, teknik pernafasan juga dilakukan setiap perubahan postur seperti posisi "downward facing dog" menarik nafas kemudian beralih ke "chaturangga dandasana" (bertumpu pada telapak tangan dan kaki) seperti hal nya posisi push up dan turun perlahan sambil mengeluarkan nafas, kemudian ke posisi "cobra" menarik nafas lagi, kembali ke posisi downward facing dog sambil mengeluarkan nafas. Dari postur-postur tadi, anggota diajarkan mengatur pernafasan sambil terus melakukan gerakangerakan yoga dengan ritme perlahan.

b. Instruksi Postur Yoga

Aliran pada kelas yoga di health club fatimah kota serang adalah vinyasa modifikasi dimana pada setiap pertemuan instruktur akan mengisntruksikan variasi gerakan namun tetap di ranah postur yoga, jenis modifikasi yoga vinyasa tersebut adalah: pertama, yoga cardio yang mengutamakan target pengurangan kalori dan pembentukan tubuh yang proporsional. Biasanya instruktur menggunakan jam yang dapat menghitung pembakaran kalori dengan target penurunan kalori sekitar 400-500 kalori.

Kedua, yoga dance atau disebut juga tarian jiwa dimana modifikasi yoga ini lebih mengalir pada setiap gerakannya sehingga terlihat seperti orang yang menari dengan sepenuh jiwanya. Ketiga, power yoga yaitu postur yoga vinyasa yang mengutamakan gerakan penuh dengan energi serta melatih kekuatan tangan dan kaki. Keempat, yoga with dumble, pada yoga ini menggunakan alat pendukung yaitu dumble kecil dengan berat tidak lebih dari 2 kilogram yang biasanya mengutamakan gerakan pada lengan untuk memperkuat otot lengan.

Kelima, yoga with rubber atau menggunakan karet khusus yang biasa dipakai pada latihan yoga. Intruktur akan memberi rubber sesuai dengan kemampuan dan kelenturan anggotanya dengan memberikan rubber yang berbeda warna, seperti rubber hijau untuk pemula karena karetnya lebih lentur, rubber merah untuk anggota yang sudah advance karena bahan karetnya lebih keras sehingga butuh kekuatan lebih untuk menariknya. Keenam, yoga wheel adalah yoga vinyasa modifikasi yang menggunakan roda khusus latihan yoga dengan berat tidak lebih dari setengah kilogram, yoga ini memfokuskan pada keseimbangan dan keselarasan postur tubuh. Ketujuh, yoga detox, yoga ini fokus pada proses detox ala yoga dengan postur "rabbit" posisi menjulurkan lidah sambil 
mengeluarkan nafas dari perut, efek dari yoga detox biasanya akan menimbulkan rasa mual dan pusing karena detoxisasi ini

\begin{tabular}{|c|c|c|c|}
\hline $\begin{array}{l}\mathrm{N} \\
\mathrm{O}\end{array}$ & $\begin{array}{l}\text { Yoga } \\
\text { Vinyas } \\
\text { a } \\
\text { Modifi } \\
\text { kasi }\end{array}$ & $\begin{array}{l}\text { Fokus } \\
\text { Postur }\end{array}$ & $\begin{array}{l}\text { Keterang } \\
\text { an }\end{array}$ \\
\hline 1 & $\begin{array}{l}\text { Yoga } \\
\text { cardio }\end{array}$ & $\begin{array}{l}\text { Gerakan } \\
\text { mengencan } \\
\text { gkan otot- } \\
\text { otot }\end{array}$ & $\begin{array}{l}\text { Ritme } \\
\text { lebih } \\
\text { cepat dan } \\
\text { bertenaga }\end{array}$ \\
\hline 2 & $\begin{array}{l}\text { Yoga } \\
\text { dance }\end{array}$ & $\begin{array}{l}\text { Gerakan } \\
\text { yoga lebih } \\
\text { mengalir }\end{array}$ & $\begin{array}{l}\text { Menggab } \\
\text { ungkan } \\
\text { yoga, } \\
\text { nafas dan } \\
\text { tarian }\end{array}$ \\
\hline 3 & $\begin{array}{l}\text { Power } \\
\text { yoga }\end{array}$ & $\begin{array}{l}\text { Gerakan } \\
\text { yoga } \\
\text { variasi }\end{array}$ & $\begin{array}{l}\text { Penekana } \\
\text { n pada } \\
\text { kekuatan } \\
\text { gerakan } \\
\text { dan } \\
\text { fleksibilit } \\
\text { as }\end{array}$ \\
\hline 4 & $\begin{array}{l}\text { Yoga } \\
\text { with } \\
\text { dumbel } \\
1\end{array}$ & $\begin{array}{l}\text { Gerakan } \\
\text { membuka } \\
\text { dada, bahu } \\
\text { dan } \\
\text { punggung }\end{array}$ & $\begin{array}{l}\text { Membant } \\
\text { u } \\
\text { menguatk } \\
\text { an otot } \\
\text { lengan, } \\
\text { dada, dan } \\
\text { punggung }\end{array}$ \\
\hline 5 & $\begin{array}{l}\text { Yoga } \\
\text { with } \\
\text { rubber }\end{array}$ & $\begin{array}{l}\text { Gerakan } \\
\text { kekuatan } \\
\text { lengan dan } \\
\text { tangan }\end{array}$ & $\begin{array}{l}\text { Membant } \\
\mathrm{u} \\
\text { menguatk } \\
\text { an otot } \\
\text { lengan }\end{array}$ \\
\hline 6 & $\begin{array}{l}\text { Yoga } \\
\text { wheel }\end{array}$ & $\begin{array}{l}\text { Gerakan } \\
\text { telentang } \\
\text { dengan } \\
\text { membuka } \\
\text { dada dan } \\
\text { tangan }\end{array}$ & $\begin{array}{l}\text { Dapat } \\
\text { meregang } \\
\text { kan dan } \\
\text { memijat } \\
\text { sesuai } \\
\text { tulang } \\
\text { belakang } \\
\end{array}$ \\
\hline 7 & $\begin{array}{l}\text { Yoga } \\
\text { detox }\end{array}$ & $\begin{array}{l}\text { Gerakan } \\
\text { yoga twist } \\
\text { (memutar } \\
\text { tulang } \\
\text { belakang) } \\
\text { rabbit pose }\end{array}$ & $\begin{array}{l}\text { Menstimu } \\
\text { lus } \\
\text { kinerja } \\
\text { organ } \\
\text { hati, } \\
\text { ginjal, } \\
\text { usus } \\
\text { besar dan }\end{array}$ \\
\hline
\end{tabular}

membersihkan asam lambung berlebih di perut dan melancarkan aliran darah.

\section{\begin{tabular}{|l|l|l|l|}
\hline & & & paru-paru \\
\hline
\end{tabular} \\ Tabel 3.1 \\ Yoga Vinyasa Modifikasi}

c. Bahasa Instruksi Yoga

Bahasa instruksi pada kelas yoga di health club fatimah serang menggunakan dua bahasa, yaitu bahasa inggris dan bahasa sankrit. Bahasa sankrit dalam yoga maksudnya adalah Yoga berasal dari bahasa sansekerta yang muncul di India, oleh karena itu istilah-istilah dalam yoga pun berbahasa sansekerta atau biasa disebut bahasa sankrit. Sementara istilah yoga dalam bahasa inggris merupakan hasil modifikasi masyarakat eropa dan amerika dalam mengembangkan dan memudahkan mengenal istilah yoga dalam bahasa inggris. Instruktur terbiasa menyebut istilah yoga dengan menggunakan bahasa inggris untuk instruksi gerakan dan menggunakan bahasa sankrit pada setiap pose.

\begin{tabular}{|c|l|l|l|}
\hline N & \multicolumn{2}{|c|}{ Istilah Instruksi Yoga } & \\
\cline { 2 - 4 } & $\begin{array}{l}\text { Bahasa } \\
\text { Inggris }\end{array}$ & $\begin{array}{l}\text { Bahasa } \\
\text { Sankrit }\end{array}$ & $\begin{array}{l}\text { Instr } \\
\text { uksi }\end{array}$ \\
\hline 1 & $\begin{array}{l}\text { Standing } \\
\text { mountai } \\
\text { npose }\end{array}$ & Tadasana & $\begin{array}{l}\text { Inhal } \\
\mathrm{e}\end{array}$ \\
\hline 2 & $\begin{array}{l}\text { Upward } \\
\text { salut } \\
\text { pose }\end{array}$ & $\begin{array}{l}\text { Urdhva } \\
\text { hastasana }\end{array}$ & $\begin{array}{l}\text { Exhal } \\
\text { e - } \\
\text { inhal } \\
e\end{array}$ \\
\hline 3 & $\begin{array}{l}\text { Standing } \\
\text { forward } \\
\text { bend }\end{array}$ & Uttanasana & $\begin{array}{l}\text { Exhal } \\
\mathrm{e}- \\
\text { inhal } \\
\mathrm{e}\end{array}$ \\
\hline 4 & $\begin{array}{l}\text { Plank } \\
\text { pose }\end{array}$ & $\begin{array}{l}\text { Kumbhakas } \\
\text { ana }\end{array}$ & $\begin{array}{l}\text { Exhal } \\
\mathrm{e} \\
\text { inhal } \\
\mathrm{e}\end{array}$ \\
\hline 5 & For & Chaturanga & Exhal \\
\hline
\end{tabular}




\begin{tabular}{|l|l|l|l|}
\hline & $\begin{array}{l}\text { limbed } \\
\text { staff } \\
\text { pose }\end{array}$ & dandasana & $\mathrm{e}$ \\
\hline 6 & $\begin{array}{l}\text { Cobra } \\
\text { pose }\end{array}$ & $\begin{array}{l}\text { Bhujangasa } \\
\text { na }\end{array}$ & $\begin{array}{l}\text { Inhal } \\
\mathrm{e}\end{array}$ \\
\hline 7 & $\begin{array}{l}\text { Downwa } \\
\text { rd facing } \\
\text { dog pose }\end{array}$ & $\begin{array}{l}\text { Urdhva } \\
\text { mukha } \\
\text { svanasana }\end{array}$ & $\begin{array}{l}\text { Exhal } \\
\mathrm{e}\end{array}$ \\
\hline 8 & $\begin{array}{l}\text { Step or } \\
\text { jump to } \\
\text { forward } \\
\text { bend }\end{array}$ & Uttanasana & $\begin{array}{l}\text { Inhal } \\
\mathrm{e}\end{array}$ \\
\hline 9 & $\begin{array}{l}\text { Child } \\
\text { pose }\end{array}$ & Balasana & $\begin{array}{l}\text { Norm } \\
\text { al } \\
\text { breat } \\
\text { hing }\end{array}$ \\
\hline
\end{tabular}

Tabel 3.2

Bahasa Instruksi Yoga

Jika diawal latihan bagi anggota baru akan terasa asing mendengar istilahistilah instruksi yoga dengan Bahasa Inggris maupun Bahasa Sankrit, namun seiring intensitas latihan maka anggota akan terbiasa mengikuti gerakan yoga hanya dengan mendengarkan instruksi.

\section{KESIMPULAN}

Olahraga yoga merupakan latihan olah pernafasan dan tubuh yang telah ada sejak ribuan tahun lalu lalu kemudian tersebar ke Eropa dan Amerika juga Asia termasuk Indonesia, dimana yoga identik dengan meditasi dan ritual agama Hindu. Melalui penyebaran tersebut yoga telah termodifikasi dari makna, gerakan postur sampai penggunaan bahasa instruksinya.

1. Instruksi cara berfikir instruktur yoga pada anggotanya adalah yoga untuk kesehatan organ-organ tubuh, yoga adalah kegiatan olah seni dan jiwa untuk menciptakan keselarasan dan meningkatkan kekuatan tubuh, dan terakhir non competitive of yoga artinya tujuan beryoga bukan untukk kompetisi namun mengutamakan semangat kesehatan dan keseimbangan tubuh.

2. Instruksi makna beryoga, maknanya bahwa setiap postur yang diajarkan memiliki arti yang berbeda, baik dari tubuh dan pikiran agar dapat mengontrol emosi sekaligus tubuh yang sehat

3. Dalam pelaksanaan instruksional yoga, pertama ada instruksi teknik pernafasan yang mengutamakan pengaturan nafas perlahan di setiap gerakan yoga, kedua instruksi postur yoga vinyasa yang telah dimodifikasi menjadi beberapa gerakan yoga seperti, yoga cardio, power yoga, yoga with rubber, yoga wheel, yoga detox, yoga with dumbell, dan yoga dance. Ketiga, instruksi latihan menggunakan dua bahasa dalam menyebutkan istilah-istilah gerakan yoga yaitu menggunakan Bahasa Inggris dan Bahasa Sankrit.

\section{REFERENSI}

Kinasih, Arum Sukma. Pengaruh Latihan Yoga Terhadap Peningkatan Kualitas Hidup. Buletin Psikologi Volume 18 no.1. 2010.

K.Yin, Robert. Studi Kasus, Desain dan Metode. Jakarta. Rajagrafindo. 2005.

Yusuf, Pawit M. Komunikasi Intstruksional, Teori dan Praktik. Jakarta. Bumi Aksara. 2010

Wahyuningsih, Sri. Metode Penelitian Studi Kasus (Konsep, Teori Psikologi Komunikasi, dan Contoh Penelitiannya). Universitas Trunojoyo Madura. 2013

Zakiah, Kiki. Komunikasi Instruksional Dalam Proses Pembelajaran Mahasiswa. Mediator Volume 7 No. 1.2006 